\title{
Professional competencies in the model of forming a professional-subjective attitude of the medical university students
}

\author{
Ekaterina Bondarenko ${ }^{1 *}$, Lyubov Khoronko ${ }^{2}$, Aleksandra Artyukhina ${ }^{1}$, and Yana Rodye $^{3}$ \\ ${ }^{1}$ Volgograd State Medical University, Biomedical faculty, 400131, Volgograd, Russian \\ Federation \\ 2 Don State Technical University, Faculty "Psychology, Pedagogy and Defectology", \\ 344000, Rostov on Don \\ ${ }^{3}$ Richmond Hill Naturopathic Clinic, 10168, Toronto, Canada
}

\begin{abstract}
The article deals with the categories of competency as the ability to apply knowledge, skills and personal qualities for successful and future professional activities and students' professional-subjective attitude as an integrative personality trait, manifested in the willingness to master professional experience and based on the independent development of professional and personal qualities through initiative inclusion in creative professionally oriented activities. The formation of a professionalsubjective attitude provides the basis for the development of professional competencies, which, in turn, are the key goal and the result of the educational process. The paper proposes a model for the formation of the professional-subjective attitude of the medical university students. The motivational, cognitive, professional-practical and professional-medical components are distinguished. The motivational component includes the motivation of a student to learn, to get a profession, to form a professionalsubjective attitude and also involves self-estimation of the attitude by the student himself. The cognitive component considers the process of forming a professional-subjective attitude in the student's educational activity (moreover, this process is conscious). The professional-practical component involves the formation of a professional-subjective attitude of students through activities in the educational environment attitude and problems solving.
\end{abstract}

\section{Introduction}

The educational process currently implies a tendency of a personal-professional orientation in the formation of a student as a specialist, taking into account his interests and abilities. At the same time, the educational process is closely connected with the competency-based

* Corresponding author: moni-moni@yandex.ru 
approach, in which the mastery of basic and professional competencies is considered as the main goal and the result of professional education.

The document "Concept of the Federal Target Program for the Development of Education for 2016-2020" (approved by the order of the Government of the Russian Federation dated December 29, 2014 No. 2765-p) states that one of the tools for the effective implementation of the program is the creation of the conditions (educational environment) and opportunities for personal and professional development while guaranteeing their quality. A personality-oriented model of education will significantly increase the competitiveness of the individual.

\section{The concept and and methodology of the study}

The process of development of the professional-subjective attitude of a student as a future specialist can be considered through the prism of the following parameters: conscious choice of a profession and the formation of a professional orientation; activity of cognitive processes, readiness for self-studying and self-development; acquisition of professionally valuable qualities; development of readiness for the professional activities.

Important professional and personal qualities of a doctor are described by professional competencies that medical students should develop during the learning process, therefore assessment of the level of their formation is of great importance. The objective of our study is to identify the formation of professional and personal qualities of a doctor. The questionnaire entitled, "Important profession-related qualities of a doctor" was used in the research work. The present study involved 240 students including 140 students of the faculty of General medicine, 50 students of Biomedical faculty and 50 students of Pharmaceutical faculty.

Successful implementation of the Federal State Educational Standards of higher education in terms of a competency-based approach implies that in addition to mastering knowledge, skills and competencies there is a need for a systematic personal and professional development of a future specialist. A formed professional and subjective attitude will provide the basis for this development. Interrelation of these concepts in scientific pedagogical studies will be considered further in the article. Competency is a measure of competencies mastering, and competencies are a means of describing the objects and the types of professional activities to be mastered in the process of a specialist training [1]. Many works analysis let us make the conclusion that a competence is a certain sphere or a circle of issues for an authorized person to solve $[2,3,4]$.

V.I. Baidenko defines competency as:

1. The ability to do something well and effectively in a wide range of contexts with a high degree of self-regulation, self-reflection, self-estimation, with a quick, flexible and adaptive response to the dynamics of the circumstances and the environment.

2. Compliance with the qualification characteristics, taking into account the requirements of local and regional (federal) needs and requests of labor markets.

3. The ability to perform special activities depending on the tasks and problem situations $[5,6]$.

It should be noted that distinguishes the following key educational competences: axiological-reasoning competence, general cultural competence, educational cognitive competence, informational competence, communicative competence, social and labor competence, personal self-improvement competency [7-9]. It should be noted that the requirements for the results of mastering the basic educational programs by a graduate in the specialty 31.05.01 "General Medicine" indicate that the graduate must have both general cultural competencies and professional competencies (general professional competencies, as well as those in preventive, diagnostic, medical, rehabilitative, 
psychological, pedagogical, management and research activities). The competency-based approach implemented in professional training of future doctors, involves focusing on the international quality standards for a specialist training. In this regard, the formation of professionally important qualities is an indispensible component of a student's professional competence.

According to authors, the medical activity imposes specific requirements to the subject of the educational process. It requires a sound and diverse education background, continuity of the professionalization process, and performing activities that are diverse in structure and techniques $[6,10,11,12,13]$.

\section{Results and and discussion}

As a part of the experiment, a survey was conducted at the Volgograd State Medical University to study the professional and personal qualities of a doctor. The results of the survey indicate that $16 \%$ of medical students demonstrate an average, acceptable level of professional orientation, the majority of the students (79\%) showing the optimal level, and $5 \%$ of students with a low level of professional orientation.

The following aspects were highly rated (3-4 points) by the surveyed students: ability to work in a team, to cooperate at any level $(87 \%)$; ability to take individual decisions $(85 \%$ of the respondents); readiness for independent actions, fulfillment of tasks innovative in nature $(85 \%)$; ability to analyze, use logical thinking and to assess the consequences of the decisions (94\%); self-organization, healthy lifestyle $(63 \%)$; ability for constant selfeducation, awareness in various areas of public life (72\%); positive attitude to patients and their families (87\%); abilities of written and oral communication, public address $(61 \%)$; ability to use computer technologies in different spheres, including the professional one $(52 \%)$; readiness for organizational and managerial work $(65 \%)$; deep theoretical knowledge in the chosen professional field (89\%); competence in areas related to the chosen specialty (80\%); awareness of the rules and principles of deontology $(87 \%)$; good command of professional practical skills $(89 \%)$; involvement in science and research activities in professional issues ( $78 \%$ of the students).

Thus, the specificity of the competency-based approach in education is the explorative, practice-oriented approach of educational activities. The following components of competency-based experience were identified in the study:

- experience in the search for educational and scientific information (starting with a competent work with the textbook and the resources of the scientific library of the department and the university, and proceeding to the use of the resources of the Internet and the educational portal of the university);

- operational experience (the ability to choose adequate methods of educational, cognitive and research activities, to make decisions and predict their consequences, to assess the prospects and consequences of the decisions and actions);

- experience of self-estimation and reflection;

- experience in choosing educational strategies;

- experience of creative activity (acquired both in the educational process, and due to the "impulses of development" provided by the educational environment contests, participation in research work of the students' scientific societies, etc.);

- experience of cooperation (arises while working in a team, being expressed in the ability to join efforts, to solve problems jointly).

Taking into consideration the results of psychological and pedagogical investigations on the problem and our own pedagogical experience, we have developed an understanding 
of the professional-subjective attitude.

The professional-subjective attitude of a student is self-awareness as a subject acquiring a profession that is combining the development of professional knowledge, skills and independent development of professional and personal qualities.

The process of development of the professional-subjective attitude of a student as a future specialist can be considered through the prism of the following parameters: conscious choice of a profession and the formation of a professional orientation; activity of cognitive processes, readiness for self-studying and self-development; acquisition of professionally valuable qualities; development of readiness for the professional activities.

A theoretical model of the professional-subjective attitude development was proposed, which includes 2 interconnected units: a target unit characterizing the professionalsubjective attitude of a medical student and a process unit - a model for the development of a professional-subjective attitude of a medical student.

The analysis of the professional-subjective attitude of a medical student suggests that it is structured by such psychological components as: motivational - a set of motives for learning, obtaining a profession and motivation to form a professional-subjective attitude, self-estimation of the attitude; cognitive - including a system of knowledge and experience of cognitive activity; professional-practical - means of self-development in the process of educational activity; professional-medical - a system of knowledge about the culture of health, experience of health-conscious activities.

Taking into account the characteristics of the professional-subjective attitude of medical students, the criteria and levels of its formation are substantiated. The definition of the criteria was based on the main manifestations of the professional-subjective attitude of a medical student in value-oriented, educational, behavioral spheres, in the field of selfregulation. In fact, this attitude is manifested in how the student studies, what values he is guided by, what types of activities he is involved in, and how he organizes his communication in the educational and professional environment, how he manages himself in the process of professional development.

Considering the above mentioned, the following criteria of development of professional-subjective attitude were distinguished: the need for self-realization as a subject of the chosen professional sphere; the importance of mastering the educational content to achieve the life goals; the adequacy of professional self-assessment; the development of professionally important qualities of future doctors; professionally oriented behavior in various spheres of life and communication; development of the personal system of selforganization in the process of mastering a profession. The study identified three levels of the development of students' professional-subjective attitude.

Students with a low level of subjective attitude are characterized by a passive attitude towards educational and professional activities, lack of interest for professional development, lack of readiness for self-development, prevalence of external motives in choosing a profession - "desire to get a diploma of education", "desire of parents and relatives". At the beginning of the experimental work, such students accounted for $40.6 \%$ $(39.4 \%)$ of the total number of students.

Students demonstrating the average (acceptable) level are characterized by a tendency of conscious understanding of the social and personal significance of the medical profession, showing interest in professional activities. But they lack the ability of independent solving of cognitive tasks. These students are interested in self-development, but the skills of self-improvement are not enough developed. Professional orientation is characterized by a predominance of internal motives in obtaining a profession. Students of this group do not always take the initiative in doing independent work. At the beginning of the experimental work, such students accounted for approximately $40.6 \%(41.2 \%)$ of the total number of students. 


\section{Conclusion}

The high level of subjective attitude was demonstrated by students with a developed readiness for professional activity, which involves a high level of development of motivation and professionally valuable personal traits. The needs for self-actualization are developed, the abilities for self-knowledge and self-development are observed. The students are characterized by a conscious choice of profession. In the framework of the professional orientation the students demonstrate the dominant motives in choosing a profession - "the desire to actualize personal abilities", "the desire to achieve a high status in the society", "the need for continuous growth". These students are responsible for the performance of his duties, independent in finding ways to solve the tasks, showing activity and creativity. At the beginning of the experimental work, such students made up $18.8 \%$ $(19.4 \%)$ of the total number of students.

The proposed model of the development of the professional-subjective attitude will serve as the basis for the professional competencies, which include not only the development of knowledge and skills, but also the development of professionally significant qualities in educational and professional activities.

\section{References}

1. I. D. Lapteva, Pedagogical education and science. 4, 35-38 (2007)

2. X. Du, F.S. Cyprian, S. Kassab, A. Al-Moslih, M.F. Abu-Hijleh, H. Hamdy, J Appl Res High Educ. (2019) doi: https://doi.org/10.1108/JARHE-07-2018-0114

3. A.K. Markova, The psychology of professionalism (Moscow, 1996)

4. R.N. Ghimire, R.A. Martin, Journal of International Agricultural and Extension Education 18(2), 5-17 (2011)

5. N.J. Kaslow, N.J. Rubin, M. Bebeau, I.W. Leigh, J. Lichtenberg, P.D. Nelson, Professional Psychology: Research and Practice, 38, 441-451 (2007)

6. V.I. Baydenko, Higher education in Russia 11, 3-13 (2004)

7. S.E. Kassab, D. Xiangyun, E. Toft, F. Cyprian, A. Al-Moslih1, H. Schmidt, H. Hamdy, M. Abu-Hijleh, MC Medical Education 19(155), 2-8 (2019)

8. A. V. Khutorskoy. Higher education in Russia 12, 9-16 (2017)

9. C. Roberts, C. Jorm, S. Gentilcore, J. Crossley, Med Educ. 51(4), 390-400 (2017)

10. E. K. Khenner, The Education and Science Journal 2(20), 9-31 (2018)

11. Y.B. Omarova, D.G. Toktarbayeva, I.V. Rybina, A. Saliyevaa, F.N. Zhumabekova, International Journal of Environmental and Science Education 11(14), 6651-6662 (2016)

12. B.A. Yas'ko, Psychology of the personality and the work of a doctor (Rostov-onDon, 2005)

13. S. Alvarez, J.-H. Schultz, Anatomical Sciences Education (2019), doi: http://dx.doi.org/10.1002/ase.1798 